\title{
Probabilistic Seismic Hazard Assessment for Amaravathi Region, Andhra Pradesh
}

\author{
K. Srikanth, S.V. Surendhar, M. Shiva Rama Krishna, R. Ramakrishnan
}

\begin{abstract}
This article explains an analytical attempt that estimates seismic hazard for Amaravathi city. The present study has been carried out contemplating the available faults and epicentral data within a radius of $300 \mathrm{~km}$ of the Amaravathi region. The homogenous earthquake catalogue has been prepared for Amaravathi region by Steep's method. The seismic hazard parameters " $a$ " and " $b$ " for Amaravathi city were evaluated by Gutenberg-Ritcher method. The " $a$ " and " $b$ " values obtained as 4.69, 0.6468 respectively. The total 353 epicenters and 31 faults were considered in this seismic analysis for the estimate of PSHA for Amaravathi. The ground motion produced by the faults at this site has been estimated by using the regionspecific Ground Motion Prediction Equation (GMPE) developed by the raghukanth and lyenger (2007). The probability of occurrence of different magnitude classes was estimated. The hazard curves and mean annual rate of exceedance for Peak Ground Acceleration were calculated by using ground motion estimated in this area. The Uniform Hazard Response Spectrum (UHRS) for the ranging time periods between $0.1-4$ seconds was prepared. PGA values for Amaravati region was found to be in between $0.001 \mathrm{~g}$ to $0.3 \mathrm{~g}$ from seismic hazard map that was prepared in this study.
\end{abstract}

Keywords: Peak Ground Acceleration, PSHA, Hazard Assessment, seismicity, Amaravathi city.

\section{INTRODUCTION}

The study area lies in the right banks of the Krishna River. This city positioned $22 \mathrm{~km}$ farfrom the secretariat of Andhra Pradesh. Amaravathi region is affected by low to high earthquakes in past such as bhadrachalam earthquake of moment magnitude $(\mathrm{Mw}=5.7)$ at $17.81 \mathrm{~N}, 80.670 \mathrm{E}$, depth $=25.00 \mathrm{~km}$ in 1969 , Ongole earthquake of moment magnitude $(\mathrm{Mw}=5.5)$ on April 1905 and Ongole-Kanuparti earthquake of magnitude (Mw=5.2) on 27 March 1967. Amaravati city has been settled in zoneIII as per (IS 18932016). The fixed peak ground acceleration for this region as $0.16 \mathrm{~g}$ (as per IS1893-2016). Amaravathi city is situated in southern India which is a region with low to moderate seismic activity.This region experienced506 earthquakes of different magnitude ranges $(\mathrm{Mw}=1.25-6.25)$ from 1800 to2015. The seismic hazard analysis and subsequent preparation seismic hazard map for Amaravathi is necessary for the evaluation of seismic design load and to perform earthquake resistant design of important structures like dam, nuclear reactor etc... This paper elaborates the probabilistic seismic hazard assessment (PSHA) for Amaravathi

Revised Manuscript Received on April 12, 2019.

K. Srikanth, P.G.Student, VFSTR University, Vadlamudi, Andhrapradesh.522213, India. (kasarabadasrikanth65@gmail.com)

S.V. Surendhar, Asst.Professsor, VFSTR University, Vadlamudi, Andhrapradesh.522213, India.(svsurendhar@gmail.com)

M. Shiva Rama Krishna ,Asst.Professsor, VFSTR University, Vadlamudi, Andhrapradesh.522213, India. (shivaram.vu@gmail.com)

R. Ramakrishnan,Asst.Professor, Amrita University, Coimbatore, Tamil Nadu. India641112. (ramakrishnan19490@gmail.com)
city.Hence the proposed study is useful in the present and future development of small and large structures and nuclear plants, power plants to be constructed in Amaravathi region.There are no micro-zonation and mesozonation studies have been carried out in the pastfor Amaravathi region hence the current study of PSHA analysis on Amaravati region will be significant addition to the researches of PSHA for different regions in India that has been carried out by various researchers. Reliability analysis (PSHA) allows size and location uncertainties of the earthquake which has been taking into hazard analysis to rate the seismic risk at the location. The seismic risk curves and uniform hazard response spectrum (UHRS) has been prepared at the chosen sites of the Amaravathi region for return periods for different spectral acceleration is prepared.

\section{STUDY AREA}

Amaravathi is the new capital city of Andhra Pradesh; it lies between the coordinates of $16.5730^{\circ} \mathrm{N}$ latitude and $80.3575^{\circ} \mathrm{E}$ longitude. This city is situated in peninsular India which is considered as a region with low to moderate seismic activity. The statistics of different earthquakes happened in Amaravathi region from (1800-2015) as shown in Fig 1.

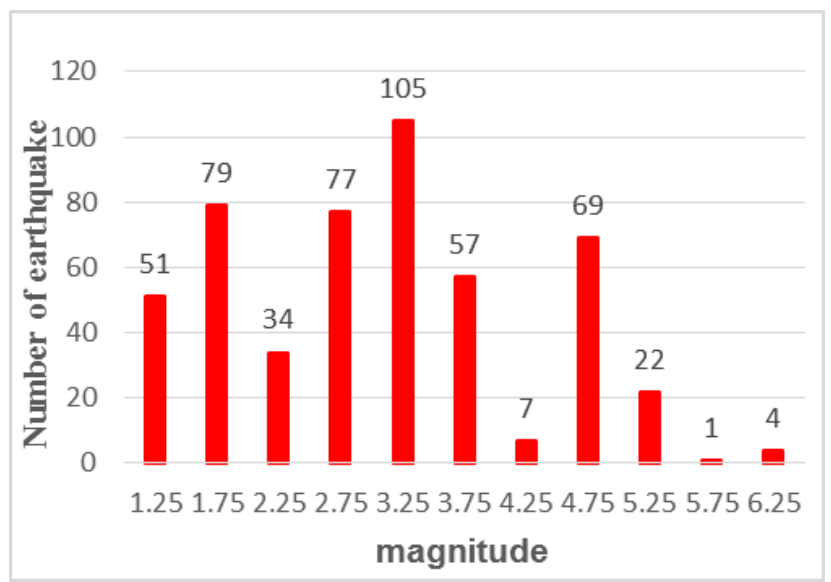

Fig.1 Statistics of the earthquake data of Amaravathi region.

Seismicity data for the Amaravathi region

The seismicity data is required for the estimation of probabilisticseismic hazard assessment (PSHA) for Amaravathi region.The seismotectonic map of India and 
open jump software has been used to developseismotectonicatlasof the area. The seismicity data include epicenters (Fig 3) and faults (Fig 2) within $300 \mathrm{~km}$ radius of Amaravathi region.

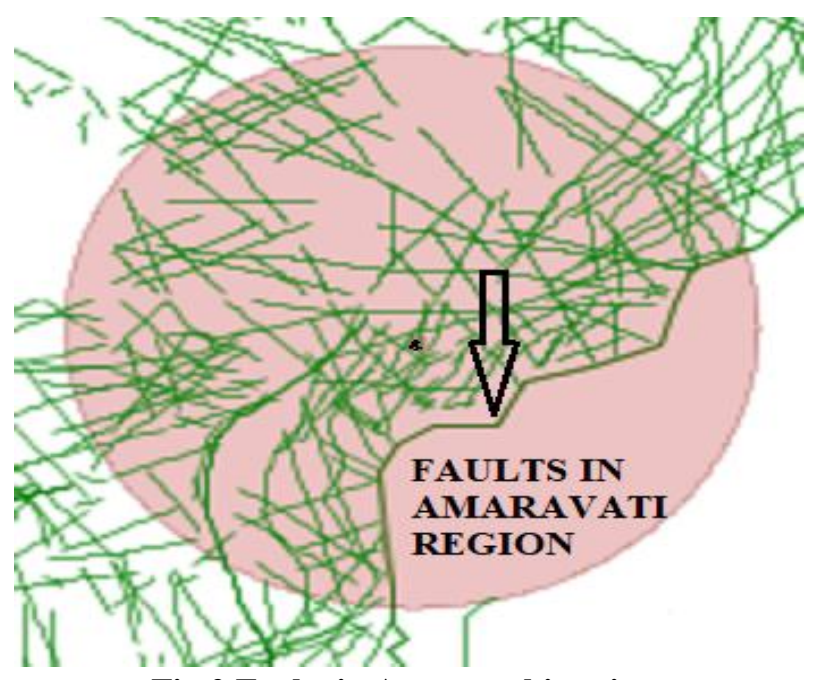

Fig.2 Faults in Amaravathi region.

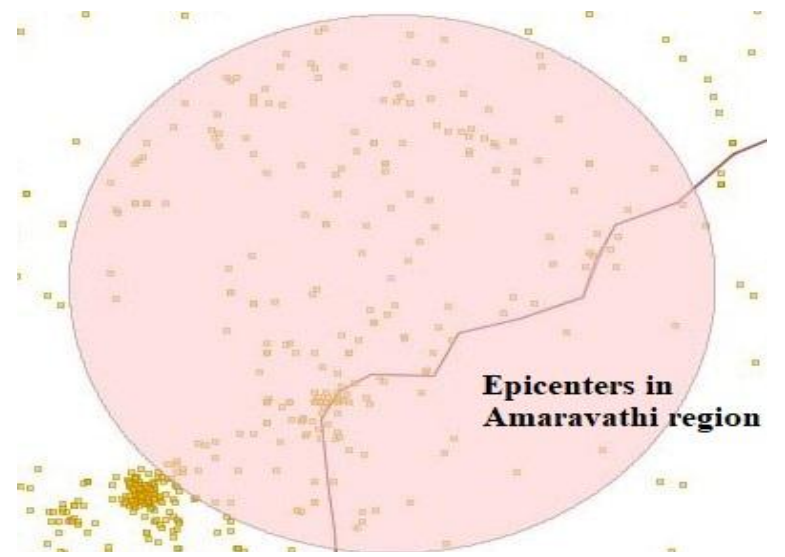

Fig.3 Epicenters in Amaravathi region.

\section{Earthquake CataloguePreparation}

For Amaravathi, the tremor catalogue has been arranged by joining and collecting the accessible data from many authorities. The earthquake information between the time intervals 1800-2015 has been gathered from different national and international agencies i.e. Geological Survey of India (GSI), and United States Geological Survey (USGS)and past literature of the earthquake catalogue for India by Sreevalsa and Sitharam (T. G. Sitharam et al., 2010).The seismic information acquired from various sources were in different magnitude scales such as moment magnitude (Mw), body-wave magnitude $(\mathrm{Mb})$, surface wave magnitude (Ms) etc. and it requires the transfiguration of this extent scales to a solitary size scale (moment magnitude scale $(\mathrm{Mw})$ ) for the investigation purposes (T. G. Sitharam et al., 2018).The various time scales of real earthquake magnitude have been transformed into homogenous moment magnitudes $(\mathrm{Mw})$ by utilizing reliable existing relations. The homogenous catalog has been developed byeliminating the foreshocks and post-quakes fromthe seismic tremor list.The completeness of the earthquake catalogue has been prepared by adopting Steep's method (1972). The availability of earthquake catalogue from different agencies is not complete, particularly for low magnitude tremors. In this method, the tremors events in the catalogue arranged in various magnitude classes and mean rate of exceedance of earthquake magnitude range are evaluated. The standard deviation vs time in years is plotted as in Fig 4

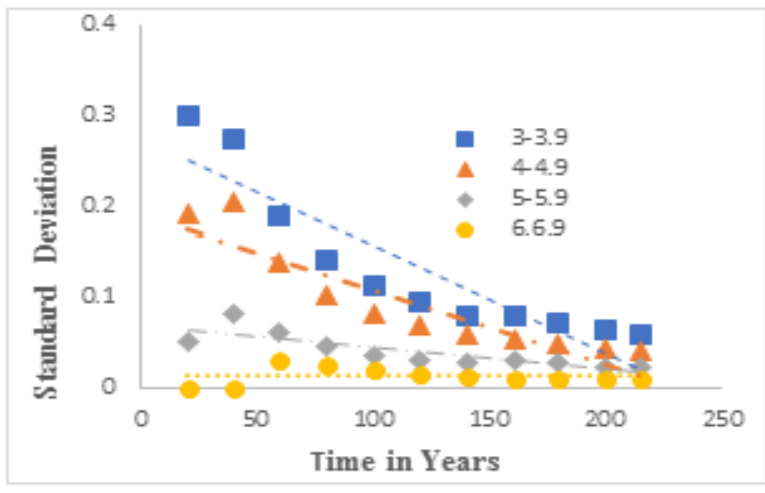

Fig. 4 Completeness analysis Using Steep's method.

\section{Estimation of seismicity parameters}

The Gutenberg-Ritcher relation is used to evaluate the seismicity parameters of the Amaravathi region. The frequency magnitude distribution (FMD) law portrays the recurrence of the event of seismic tremors of an individual size in a granted time frame. The Recurrence relation is the most critical part of seismic risk estimation. GutenbergRitcher relation allows the past seismicity information taking into account for the seismic risk evaluation, to explain the relative distribution of small and large seismic events. The Gutenberg-Ritcherreccurrence law can be written as

$$
\log (\lambda m)=a-b M
$$

Where $(\lambda m)$ is the mean annual rate of exceedance of magnitude (M). The "a", "b" are the seismicity values of the region. These values are depending on the seismic activity and earthquake time period of the region. The " $b$ " value characterizes the relative probability of small and large seismic events. The number of higher magnitudes of seismic events decreases compared to low magnitude of seismic events when "b" value rises. The "a" value is a logarithm of the number of seismic events with magnitudes equal to or more than zero. The seismicity parameters have been evaluated by Regression analysis of the past earthquake data. The hazard values for Amaravathi region evaluated by dividing the earthquake catalogue into different magnitude classes of difference $\Delta \mathrm{M}=0.5$. The magnitude classes are taken as $3.25 \leq 3.75,3.75 \leq 4.25,4.25 \leq 4.75,4.75 \leq 5.25$, $5.25 \leq 5.75,5.75 \leq 6.25$, and $6.25 \leq 6.75$. The hazard limits"a" and "b" has been evaluated to be 4.64 and 0.6468 respectively. These risk parameters can be utilized to characterize the hazard related to the area.

Published By: 


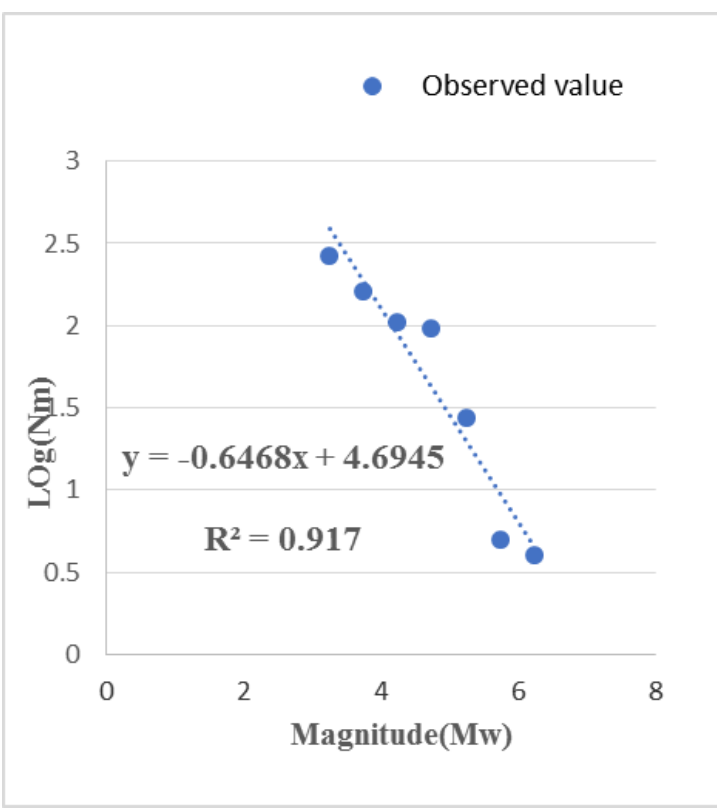

Fig .5 Gutenberg-Richter Parameters.

\section{GROUND MOTION PREDICTION EQUATION (GMPE)}

Generally, the Spectral Acceleration $(\mathrm{Sa} / \mathrm{g})$ and Peak Ground Acceleration are needed for the seismic design of structures at the site. The Peak Ground Acceleration (PGA) and Spectral Acceleration $(\mathrm{Sa} / \mathrm{g})$ values for a specific location calculated by the Ground Motion Prediction Equations. These equations changes from region to region. The Ground Motion Prediction Equations shows the changes of Peak Ground Acceleration (PGA) at a particular structural period of vibrations and various damping ratios. Many attenuation relationships are derived by the various researchers for a particular area. Raghukanth and Iyengar's attenuation relationship has been used for estimation of the ground motion produced at the site and produce hazard curves at Amaravathi region as the area situated in southern component of India (S T G Raghu Kanth et al., 2007).

$\operatorname{Ln}(\mathrm{Ybr})=\mathrm{c}_{1}+\mathrm{c}_{2}(\mathrm{M}-6)+\mathrm{c}_{3}(\mathrm{M}-6)^{2}-\ln (\mathrm{r})-\mathrm{c}_{4} \mathrm{r}+\ln (\varepsilon b r)$. (1)

Ybr is the spectral acceleration ( $\mathrm{Sa} / \mathrm{g})$ or PGA, M refers to the moment magnitude, $\varepsilon b r$ and $\mathrm{R}$ stand for error in regression and hypocentral distance respectively. The $\mathrm{C}_{1}$, $\mathrm{C} 2, \mathrm{C} 3, \mathrm{C} 4$ are the specifications specified by the raghukanth and lyenger for south India. The Peak Ground Acceleration (PGA) of each fault in Amaravathi region is calculated. 30 faults which are of higher PGA values are chosen and arranged in descending order as shown in the Table 2.

\begin{tabular}{|c|c|c|c|}
\hline $\begin{array}{c}\text { Faults } \\
\text { No }\end{array}$ & $\begin{array}{c}\text { Longitude of the } \\
\text { Faults }\end{array}$ & $\begin{array}{c}\text { Latitude of the } \\
\text { Faults }\end{array}$ & PGA \\
\hline 9 & 80.5874159 & 16.949832 & 0.16002 \\
\hline 17 & 80.0396593 & 15.244777 & 0.15922 \\
\hline 10 & 79.3970572 & 18.398101 & 0.14726 \\
\hline 21 & 80.0130022 & 16.299359 & 0.11973 \\
\hline 26 & 80.9815387 & 17.247765 & 0.10058 \\
\hline
\end{tabular}

\begin{tabular}{|c|c|c|c|}
\hline 16 & 80.8096606 & 16.652747 & 0.09833 \\
\hline 22 & 79.6866451 & 17.049939 & 0.09242 \\
\hline 24 & 79.8053568 & 16.884875 & 0.08114 \\
\hline 11 & 82.193779 & 16.950498 & 0.04311 \\
\hline 2 & 80.9658812 & 16.379852 & 0.03648 \\
\hline 31 & 82.2129763 & 18.461053 & 0.02502 \\
\hline 4 & 78.018369 & 15.802311 & 0.02401 \\
\hline 3 & 81.1859883 & 16.153343 & 0.02244 \\
\hline 6 & 79.4687807 & 16.018004 & 0.02132 \\
\hline 25 & 81.2833533 & 16.998536 & 0.02037 \\
\hline 7 & 78.3739292 & 16.937517 & 0.00898 \\
\hline 27 & 77.9828399 & 16.34118 & 0.00626 \\
\hline 30 & 82.6136169 & 17.948645 & 0.00512 \\
\hline 14 & 78.8719371 & 16.492899 & 0.00377 \\
\hline 15 & 79.0081417 & 14.88927 & 0.00204 \\
\hline 18 & 78.7391679 & 15.766888 & 0.00183 \\
\hline 13 & 78.4237895 & 17.075881 & 0.00157 \\
\hline 23 & 79.4942029 & 14.054348 & 0.00142 \\
\hline 8 & 78.7508088 & 15.585314 & 0.0014 \\
\hline 12 & 78.7719847 & 15.512904 & 0.00126 \\
\hline 29 & 78.3528308 & 16.579808 & 0.00108 \\
\hline 28 & 78.4004981 & 15.745588 & 0.00044 \\
\hline 19 & 82.2436577 & 17.075965 & 0.00036 \\
\hline 20 & 77.7970144 & 16.977578 & 0.00023 \\
\hline 1 & 78.4480405 & 14.965875 & 0.00014 \\
\hline 5 & 78.6131393 & 14.683741 & 0.0001 \\
\hline
\end{tabular}

Table 2 - Peak Ground Acceleration (PGA) value for each fault in Amaravathi region.

\section{Probabilistic Seismic Hazard Analysis(PSHA).}

Probabilistic tectonic risk examination is also called as reliability analysis. The reliability analysis has been developed by Cornell in 1978. The seismic design load for different structures has been evaluated by utilizing the results obtained from the Probabilistic Seismic Hazard Analysis(PSHA).In the Probabilistic Seismic Hazard Analysis(PSHA), from the past few decades, the size, location, and rate of recurrence of the earthquakes have been taken into considerationfor the estimation of hazard at a site.Probabilistic Seismic Hazard Analysis(PSHA) gives a frame work in which vulnerabilities(uncertainties) were not evaluated byDeterministic Seismic Hazard Analysis(DSHA), to be recognized, measured and joined in a judicious way to give an increasingly total image of the seismic hazard.

\section{ANALYSIS AND RESULTS}

Generally, the seismic sources in the region can generate seismic events from low to high tremors. The earthquakes are generally thought to be consistently distributed inside a 
specific source zone. The probability density function (PDF) depicts the uncertainty in the source-to-site distance. The probability density function of the hypocentral distance $\mathrm{R}$ for an earthquake of magnitude $M$ is supposed to be evenly circulated along the fault. The recurrence law is used to describe the distribution of tremor size in a granted time frame.

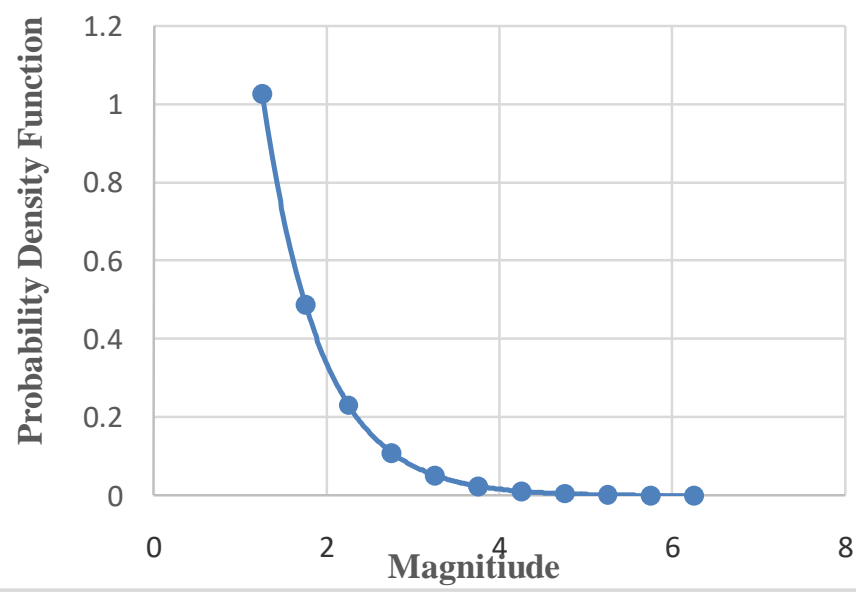

Fig. 6 Graph between probability density function and magnitude.

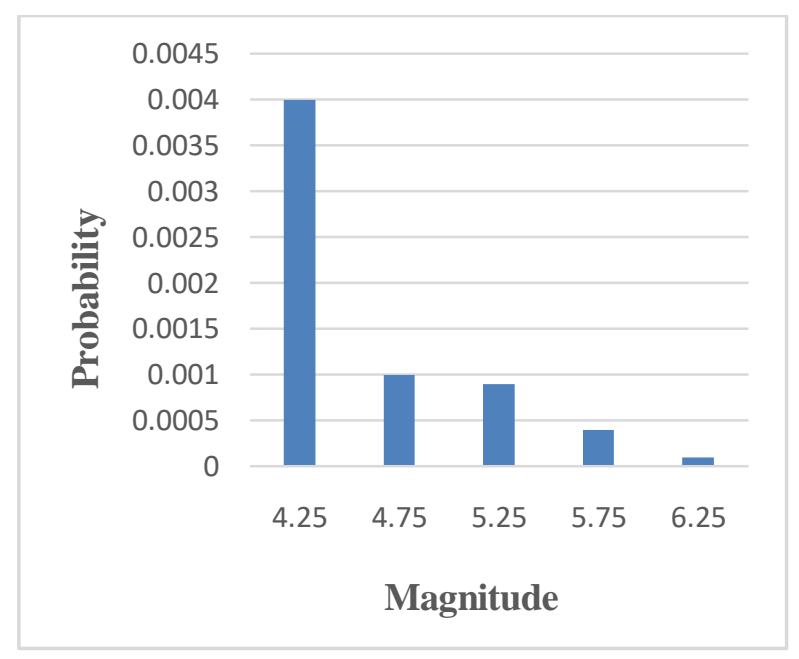

Fig.7 Graph between probability and magnitude.

\section{SEISMIC HAZARD CURVE}

The seismic hazard curve is the plot between mean annual rate of exceedance and peak ground acceleration. The plot is prepared by combining the effects of point sources (epicentres) and linear sources (faults). The hazard curve gives the likelihood of occurrence of particular PGA value for the Amaravati region.

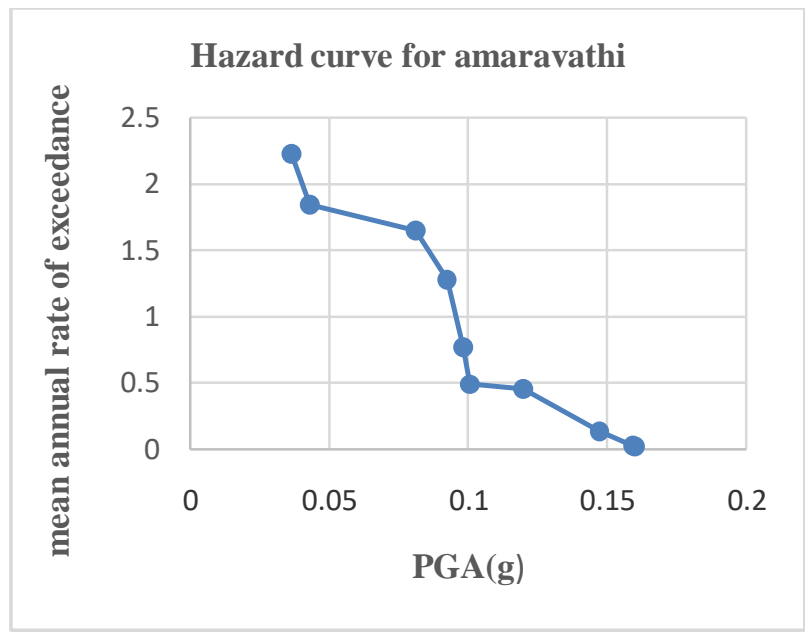

Fig.8 Combined Hazard curve for Amaravathi region.

\section{UNIFORM HAZARD RESPONSE SPECTRUM (UHRS)}

Uniform hazard response spectrum (UHRS) is created from a probabilistic ground movement examination that has an equivalent likelihood of being surpassed at every time of vibration. (SwathiPriyadarsini Putti, Neelima Satyam D and Nesanuru et al. 2017). This range is achieved from PSHA and it assesses the likelihood of exceedance of spectral acceleration $(\mathrm{Sa})$ at a site because of all conceivable future seismic tremors as pictured by the past risk situation. raghukanth and Iyengar's attenuation relationship has been utilized to calculate the uniform hazard spectrum(UHRS) for the ranging time periods between $0.1-4$ seconds was prepared.

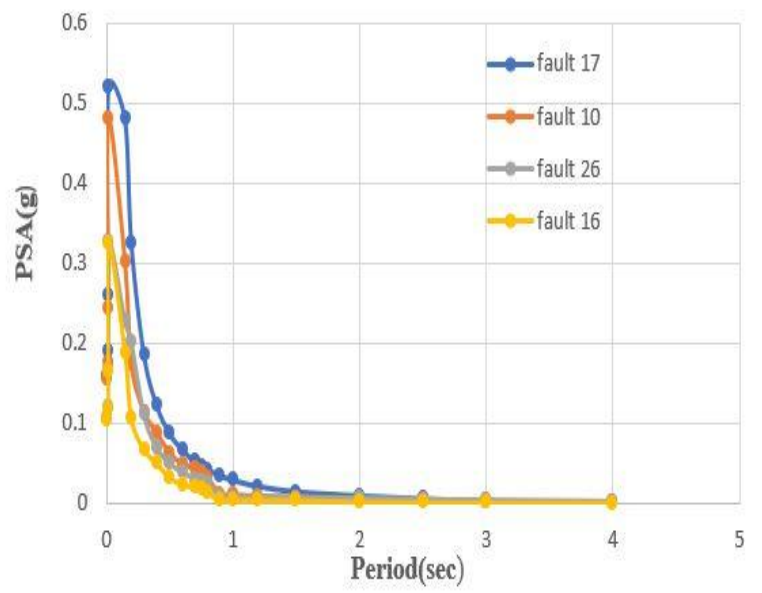

Fig. 9Uniform Hazard Response Spectrum (UHRS)for different periods. 


\section{HAZARD MAP}

Hazard map (Fig 9) is the contour of PGA values obtained from MATLAB program which analysis both point source and line source and calculates the PGA value for a grid point. In this study, grid size is chosen as $1 \mathrm{~km} \times 1 \mathrm{~km}$.

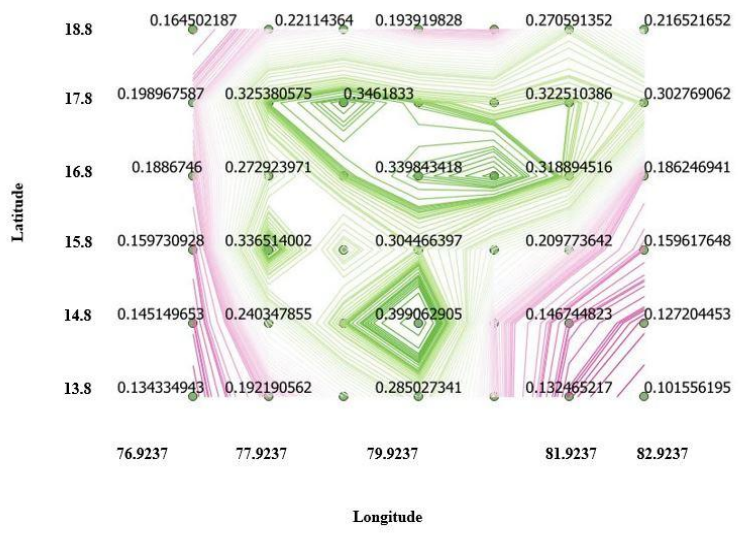

Fig 9. Hazard Map of Amaravati region

\section{CONCLUSIONS AND DISCUSSIONS:}

TheProbabilistic Seismic Hazard Analysis(PSHA) has been accomplishedwithexisting seismotectonic information. The Guttenbegparamaters have been acquired from the research are 4.69 and 0.6468 respectively.PGA values obtained in hazard map shows that the minimum PGA value is $0.1 \mathrm{~g}$ and the maximum PGA value is $0.3 \mathrm{~g}$. The Amaravati region is under zone 3 as per IS 1893-2016 with maximum PGA value of $0.16 \mathrm{~g}$ but from our study it is evident that few areas in Amaravati region has PGA values greater than $0.16 \mathrm{~g}$. The hazard curve and uniform hazard spectrum was found to be consistent with literature of other regions.

\section{REFERENCES:}

1. SwathiPriyadarsini Putti, Neelima Satyam D and NesanuruPrathimaSeismic Hazard Assessment of Vishakhapatnam-Probabilistic Approach.

2. $\quad \mathrm{S}$ T G Raghu Kanth and R N IyengarEstimation of seismic spectral acceleration in Peninsular India.

3. G. Kalyan Kumar, U. Sreedhar, G.R. Dodagoudaprobabilistic seismic hazard assessment for Chennai.

4. SreevalsaKolathayar, T G Sitharam probabilistic evaluation of seismic hazard in and around Kerala.

5. T. G. Sitharam, Naveen Comprehensive Seismic ZonationSchemes for Regions at Different ScalesSpringer Nature, 2018, James, SreevalsaKolathayar. "

6. S T G Raghu Kanth1 and R N Iyengar seismic hazard estimation for Mumbai city.

7. Kishorjaiswal and Ravi Sinha probabilistic seismic -hazard estimation for peninsular India.

8. Shravankishorgupta, Arvindkumar, Amitkumartomar seismic hazard assessment of Uttar Pradesh.

9. P.anbazhagan, j.svinod, T.G. sitharam probabilistic seismic hazard analysis for Bangalore.

10. S. T. G. Raghu Kanth. "Estimation of seismic spectral acceleration in Peninsular India", Journal of Earth System Science, 06/2007.

11. NileshShaligramPatil, Josodhir Das, Ashwani Kumar, Madan Mohan Rout and RanjitDas*Probabilistic seismic hazard assessment of Himachal Pradesh and adjoining region.
12. ChethanambaKempannaRamanna. "Probabilistic seismic hazard analysis using kernel density estimation technique for Chennai, India", Georisk Assessment and Management of Risk for Engineered Systems and Geohazards, 2011

13. S T G Raghu Kanth estimation of seismicity parameters of India.

14. Kumar Pallav1, S T G Raghukanth2 and KonjengbamDarunkumar SinghProbabilistic seismic hazard estimation of Manipur, India.

15. R. N. Iyengar* and S. Ghosh Micro zonation of earthquake hazard in Greater Delhi area.

16. Robin K. McGuire, Probabilistic Seismic Hazard Analysis and Design Earthquakes: Closing the Loop.

17. by Julian J. Bommer and Norman A. Abrahamsom, Why Do Modern Probabilistic Seismic-Hazard Analyses Often Lead to Increased Hazard Estimates?

18. Sandip das, Ishwar D. gupta, Vinay K. gupta A probabilistic seismic hazard analysis of northeast India 